\title{
SISTEMAS PRODUTIVOS TRADICIONAIS E IMERSÃO DE INTERESSES ECONÔMICOS EM RELAÇÕES SOCIAIS ${ }^{1}$
}

\author{
Gustavo Melo Silva* \\ Jorge Alexandre Barbosa Neves ${ }^{* *}$
}

\begin{abstract}
O território do município de Resende Costa (MG) convive com a tradição da produção doméstica têxtil desde o século XVIII. Entretanto, o que se constata, a partir do final do século XX, é um mercado de tecelagem tradicional. Este artigo analisa a construção social desse mercado municipal a partir de dados históricos do século XVIII e XIX, pesquisas do final do século XX e dados primários coletados em 2009 em 664 domicílios produtores e 69 estabelecimentos comerciais. Esse mercado foi construído por uma produção dispersa nos domicílios, pela divisão do trabalho e pela organização burocrática comercial que controla seus serviços produtivos para atender às pressões de consumo e solidariedade entre indivíduos com interesses econômicos imersos em relações familiares, que formam a densidade e disciplina moral desse mercado municipal de tecelagem tradicional.

PALAVRAS-CHAVE: Sistema produtivo tradicional. Sociologia econômica. Estrutura socioeconômica.
\end{abstract}

\section{INTRODUÇÃO}

Este artigo analisa o mercado de produção de utensílios domésticos e peças decorativas da tecelagem tradicional do município de Resende Costa (Minas Gerais). Esse sistema produtivo tem sua origem na produção doméstica têxtil do século XVIII na localidade então denominada Arraial da Lage, da Comarca do Rio das Mortes na Capitania de Minas Gerais. Ao processo produtivo do século XX, em comparação com os séculos XVIII e XIX, foram incorporadas inovações para atender a pressões que permearam o tecido social regional daqueles que sobrevivem desse mercado local.

* Doutor em Sociologia. Professor do Departamento de Ciências Administrativas e Contábeis (DECAC) da Universidade Federal de São João del-Rei (UFSJ).

Av. Visconde do Rio Preto, s/n, Campus Ctan. Colônia do Bengo. Cep: 36300-000 - Sao Joao Del Rei, MG Brasil gustavomelosilva@yahoo.com.br

* * Doutor em Sociologia. Professor do Departamento de Sociologia e Antropologia da Universidade Federal de Minas Gerais (UFMG). jorgeaneves@gmail.com

${ }^{1}$ Os pesquisadores contaram com apoio financeiro do Conselho Nacional de Desenvolvimento Científico e Tecnológico (CNPq), por meio do edital MCT/CNPQ 03/ 2008 - Ciências Humanas, Sociais e Sociais Aplicadas.
As mudanças que ocorreram nos domicílios e, especificamente, na produção do século XVIII para o XXI, nesse município, são consequências de incorporações na vida cotidiana de seus moradores, de pressões de mercado e sociais. Essa realidade social ocorreu por meio do capital social, organizações econômicas e redes produtivas que, no início do século XXI, se materializaram em produtos mercantis de uma tecelagem tradicional. Como veremos neste artigo, essa análise social é possível com a identificação das inter-relações familiares tradicionais que geraram confiança nas relações comerciais modernas, garantindo, assim, o ordenamento social que fica evidente na imersão dos interesses econômicos nas relações sociais. O início do povoamento desse território se deu no século XVIII. Nesse tempo social, alguns moradores se vestiam e sobreviviam com a produção doméstica têxtil. Entretanto, no final do século XX, alguns tecelões empreendedores souberam aproveitar as oportunidades do mercado turístico regional e desenvolveram atividades econômicas que associam o conhecimento têxtil tradicional, as relações familiares, a demanda por produtos turísti- 
cos e a abundância de oferta de refugos de malharias para transformar uma produção doméstica em uma produção domiciliar em massa, organizada por comerciantes locais.

Neste artigo, partimos do pressuposto de que as relações econômicas, nesse mercado, não foram precedentes de outros tipos de relações sociais. Portanto, foi considerado que os mercados só operam bem quando estão sustentados por redes sociais compostas de laços individuais polivalentes. Portanto, o referencial teórico da sociologia econômica nos permite afirmar que é um equívoco sustentar que o elemento de ordem que efetivamente existe em uma sociedade diferenciada com ampla extensão de relações de troca, como a observada nesse município, possa derivar dos interesses imediatos das partes nessas relações. Assim, foi considerado, conforme a perspectiva teórica da nova sociologia econômica, que os interesses econômicos de mercado estão imersos em redes pessoais e de grupos sociais.

A tradição têxtil desse município está relacionada com a história econômica mineira têxtil conformada no século XIX. Macedo (2006), para explicar o fenômeno histórico econômico da indústria têxtil do século XIX na Capitania de Minas Gerais, demonstra, a partir de dados das Listas Nominativas de 18311832, que a população ocupada distribuía-se em $28,34 \%$ no ramo de atividade de produção de fios e tecidos e 9,44\% na produção de peças do vestuário. Essa realidade também foi destacada na lista nominativa de 1831 do Distrito da Lage, atual município de Resende Costa, que registrava, conforme Resende (2001), 1.243 habitantes entre os quais $30,33 \%$ ocupavam postos de trabalho na produção doméstica têxtil. Desse, percentual 66,22\% correspondia a trabalho executado por mulheres. Em 2009, esse mercado pode ser compreendido pela sua representatividade econômica para o município, apresentada monetariamente na produção domiciliar pelas estimativas de renda dos trabalhadores de $\mathrm{R} \$ 3.692 .700,00$ e de faturamento domiciliar de R\$4.724.239,68. Nas organizações comerciais, existia uma possibilidade de renda anual dos trabalhadores de $\mathrm{R} \$ 1.286 .190,00$ e de faturamento anual das organizações comerciais de $\mathrm{R} \$ 7.265 .286,00$
(Silva, 2010). É bom lembrar, conforme Silva (2010), somente para efeitos de comparação e compreensão da grandeza desses valores para o município em foco, de que, no ano de 2009, esse município recebeu como fontes orçamentárias de receita, um Fundo de Participação Municipal (FPM) de R \$ 449.163,70. Conforme Silva (2010), no mercado da tecelagem tradicional desse município, existem relacionamentos sociais entre família, fornecedor e comprador, nos momentos de troca para aquisição de insumos e venda de peças ou serviços, o que interfere em suas escolhas econômicas.

Este artigo realiza uma análise do fenômeno da tecelagem tradicional como uma construção social e, como tal, consequência objetiva de uma estrutura social. A pergunta que norteou este trabalho refere-se a esse fenômeno socioeconômico, na sua manifestação no município estudado, que possuí vínculos que legitimam sua densidade e disciplina moral: Qual a relação entre tradição e modernidade no mercado de produção da tecelagem tradicional de Resende Costa (MG)? Diante desse problema de pesquisa, definiu-se, como objetivo geral, identificar a relação entre tradição e modernidade no mercado da tecelagem tradicional desse município. Este artigo está composto por esta introdução, mais três partes seguidas das considerações finais. A análise da estrutura social desse mercado como construção social constitui a primeira parte; a segunda traz o percurso metodológico; e a terceira parte, analisa a produção domiciliar tradicional e organização social da tecelagem no município em foco. No conjunto, a construção social desse mercado é apresentada e analisada a partir do tradicionalismo da técnica têxtil, das relações familiares e da modernidade comercial imersa economicamente em redes de família-fornecedor e família-comprador.

\section{RELAÇÕES SOCIAIS NOS MERCADOS: racionalidade e estrutura}

A ação racional é um ponto central das abordagens econômica e sociológica que buscam com- 
preender como são as escolhas de indivíduos em mercados que, por sua vez, são estruturados por meio de redes de relacionamentos sociais que organizam a vida econômica. Nesse contexto, o mercado é influenciado por uma realidade que emerge do contexto social, por exemplo. Conforme Granovetter (2002), isso se dá por meio de costumes, hábitos ou normas. A realidade do mercado pode ser observada sociologicamente por meio de ações e interações que os indivíduos procuram permanentemente dotar de significado (Abramovay, 2009). Além do indivíduo, grupos, relações sociais e outras variáveis como, por exemplo, gosto, conhecimento, educação, etnia e família, podem influenciar a ação econômica e os interesses individuais (Granovetter, 2002; Steiner, 2006). A compreensão da ação racional e do mercado deve considerar que os indivíduos interagem uns com os outros e com as pessoas de fora das instituições, estejam esses atores ligados diretamente aos aspectos econômicos ou indiretamente por meio de aspectos históricos, sociais ou culturais.

O mercado é um fato social que a sociologia econômica busca compreender especificamente a partir da estrutura das redes sociais que influenciam a ação coletiva com a geração e com o contexto cultural do mercado. A ação econômica é influenciada por aspectos racionais e político-econômicos que definem restrições de recursos escassos em estruturas sociais. A economia é parte integrante da sociedade, que é sua base de referência e pode ser analisada a partir de descrições e explanações feitas a partir de métodos históricos comparativos. O modelo sociológico pressupõe que a ação econômica individual é influenciada por padrões institucionais, por induções estruturais e pelo desenvolvimento social, que tem como resultados índices institucionais que consequentemente influenciam a racionalidade humana e ajustam os padrões institucionais iniciais (Smelser; Swedberg, 1994).

A escolha humana pode ser compreendida a partir da percepção do ator sobre a existência de um leque de oportunidades que os indivíduos têm e que não se reduz literalmente a uma única opção racional instrumental de maximização dos lucros.
As explicações sobre as ações econômicas podem estar nos desejos e preferências presentes nos interesses dos indivíduos, os quais possuem crenças a respeito das oportunidades e dos fatos. A abordagem sociológica da ação racional considera, portanto, que a razão é influenciada por aspectos como os movidos pelas preferências, que podem ter como consequência a própria construção social dos mercados (Elster, 1994).

As ações econômicas individuais não estão livres de pressões estruturais e suscetíveis de serem interpretadas dentro da lógica puramente aditiva e mecânica da agregação. As pressões estruturais que pesam sobre a ação econômica não se reduzem às necessidades inscritas, em dado momento do tempo, nas disponibilidades econômicas imediatas ou na instabilidade das interações. Para Bourdieu (2005a, b), existe um campo econômico, uma estrutura social, em que estão inscritas as disposições sobre a ação econômica, seja na determinação dos preços ou na definição das estratégias publicitárias. O sujeito e sua decisão econômica não se configuram como de um indivíduo isolado, mas como de um ator coletivo, seja um grupo profissional, familiar ou empresarial, que funciona como um campo que pode estar profundamente enraizado no passado sob a forma de disposições, rotinas ou por meio da história dos atores sociais (Bourdieu, 2005a, b).

A ação econômica do ator social não deixa de ser racional, já que ele tem motivos para agir como age. Conforme Nobre (2004), a concepção sociológica de racionalidade requer a satisfação de uma única assertiva, qual seja, a de que uma ação é considerada racional para a sociologia se ela for planejada. Portanto, para compreendê-la, é preciso entender qual é a atribuição de importância, ou seja, de seu interesse. A noção de que os atores sociais são interessados significa que eles acreditam nas regras do jogo social (Raud-Mattedi, 2007). A análise do mercado a partir da ação coletiva permite a incorporação de vários processos sociais para explicar os fenômenos econômicos, que não são possíveis de serem observados a partir da ação econômica do indivíduo anônimo e impessoal. 
Conforme Elster (1994), a abordagem de fenômenos econômicos a partir da escolha racional de indivíduos não é um mecanismo infalível, uma vez que o indivíduo racional pode escolher apenas o que acredita ser a melhor escolha, que pode estar na relação entre uma crença e a premissa sobre a qual ela é mantida. A racionalidade pode ser compreendida, em um contexto social, por meio da imersão estrutural dos indivíduos que possuem e dependem de um sistema cultural propagado por processos difusos ou explícitos. O problema da escolha racional de indivíduos anônimos é a impossibilidade de compreender a interdependência entre os fins pessoais e o meio social, ou seja, o sentido normativo das ações individuais. As limitações e definições normativas podem ser compreendidas no mercado por meio da caracterização social das instituições como mecanismo social de construção de um conjunto de regras. Segundo Elster (1994), as instituições nos afetam, principalmente nos forçando, induzindo ou nos capacitando a agir de alguma maneira, formando mecanismos de valores, crenças e preferências no processo decisório individual e coletivo.

A análise de mercados como construções sociais pode, entretanto, ser realizada a partir das relações entre atores e grupos e não somente por meio das normas e regras institucionalizadas. Conforme Raud-Mattedi (2005a), a sociologia econô- mica, a partir da década de 1970, retoma a análise sociológica do núcleo da vida econômica, ou seja, o mercado, que é considerado estrutura social. Granovetter (2002) retoma a abordagem sociológica dos fenômenos econômicos com discussões que mostram a influência das relações sociais na ação, resultados e instituições econômicas e impulsiona os estudos com conceitos fundamentais para a análise da vida econômica como rede e imersão.

Segundo Coleman (1990), a troca social muitas vezes não ocorre em transações isoladas de dois indivíduos, mas dentro do contexto de sistemas de troca em que existe competição por recursos escassos. Esses mercados sociais lembram, por vezes, mercados econômicos, embora frequentemente demonstrem grandes diferenças, por afir- marem a centralidade das externalidades, ou seja, os aspectos não econômicos como parâmetros essenciais para o exame da interdependência social em ambientes complexos, como também para compreender comportamentos que não se vinculam ao conceito de racionalidade instrumental, a exemplo das ações emotivas, que apontam para certas satisfações pessoais baseadas nos incentivos e prêmios resultantes da união de indivíduos que procuram um mesmo objetivo (Coleman, 1990).

Nessa perspectiva de troca social, a análise de redes de relacionamento tem como vantagem, conforme Swedberg (2004), o fato de constituir uma ferramenta flexível por meio da qual se pode lidar com um número considerável de fenômenos sociais e econômicos do mercado. A análise de redes tem sido usada, por exemplo, para explorar diversos tipos de interações econômicas que não podem ser classificadas nem como costumes nem como algum tipo de organização econômica. Essas formas sociais intermediárias são, por vezes, referidas como formas de organização em rede (Swedberg, 2004).

Essas abordagens consideram a economia como um processo que começa na produção, prossegue com a distribuição e acaba com o consumo (Swedberg, 2009). Portanto, retomam, na esfera econômica da distribuição da produção, a fecundidade dos conceitos de Polanyi (2000) de redistribuição, reciprocidade e troca. Segundo Polanyi (2000), a redistribuição costuma ser realizada pelo Estado ou alguma outra autoridade política, em que o que é redistribuído é consumido, e o crescimento da economia segue discussões políticas no lugar de uma lógica interna e independente do mercado. Já a reciprocidade implica uma forma horizontal de distribuição, a exemplo de uma economia familiar ou de parentesco; portanto, essa economia tende ao tradicionalismo e a alguma forma de equidade. E a troca é a forma de distribuição da produção que pode levar a uma economia sempre crescente (Polanyi, 2000).

De acordo com Swedberg (2009), a troca caracteriza a organização capitalista da economia, e esse tipo desenvolve sua dinâmica a partir do 
fato de que a meta final do processo econômico não é exclusivamente o consumo, mas também o lucro. E, quanto mais esse lucro é reinvestido na produção, mais dinâmica será a economia. Portanto, em outras palavras os dois mecanismos-chave desse processo social são a troca organizada, ou seja, o mercado e o ciclo de realimentação do lucro para a produção. A sociologia econômica dos mercados observa as mudanças no mecanismo de troca que alimenta o processo dinâmico do capitalismo e que tem no mercado sua instituição central. Entretanto, o mercado tem esse papel central somente quando por ele passa a maior parte do que é produzido para o consumo (Swedberg, 2009).

O mercado é analisado como estrutura social e não simplesmente como processo racional instrumental de definição de preços ou como lugar físico de relações de troca, em que a competição e as informações são perfeitas e definidas em termos de demanda e suprimento. O mercado, portanto, para a sociologia econômica, consiste em relações sociais entre indivíduos que podem aumentar e diminuir, dependendo das circunstâncias (Swedberg, 1994). Os interesses econômicos de mercado estão, para a nova sociologia econômica, imersos em redes pessoais e de grupos sociais. O mercado, portanto, não se constitui de firmas isoladas, mas de aglomerados de firmas que formam uma estrutura social (Swedberg, 1994). Conforme Granovetter (1994), um ponto importante que distingue os grupos econômicos de simples aglomerados financeiros, como os conglomerados, é a existência de solidariedade social e de uma estrutura social entre as firmas que o compõem. Essa solidariedade está imersa em laços ou vínculos sociais, como os familiares, de amizade ou étnicos. As redes sociais facilitam a circulação de informações e asseguram confiança ao limitar os comportamentos oportunistas, já que o mercado tem estrutura social (Granovetter, 2002).

A sociologia econômica revigorada por Granovetter (2002) resgata e revitaliza noções fundamentais de Polanyi (2000) de que a ação econômica é socialmente situada. Portanto, o ser huma- no não deixa de ser social com o homo economicus, e o próprio sistema econômico é mera função da organização social. Entretanto, a nova sociologia econômica analisa o papel de redes nas relações de troca mercantil, como instituições de redistribuição e coordenação que estruturam o mercado. Para Swedberg e Granovetter (1992), a rede é um conjunto regular de contratos ou conexões sociais similares entre indivíduos e grupos. Por exemplo, Granovetter (1973) identifica, no mercado de trabalho, que é menos importante estar fortemente inserido numa rede de amigos ou de parentes do que ter acesso, por meio de laços fracos, ou seja, de conhecidos, a várias redes. Os laços fracos são decisivos porque estabelecem pontes entre as redes, permitindo, assim, o acesso a universos sociais diversificados e a uma maior variedade de informações, que configuram a força dos laços fracos (Granovetter, 1973). É importante salientar que as relações sociais não passam necessariamente por relações pessoais. A dimensão social das relações econômicas decorre do fato de que, no quadro da troca mercantil, os atores econômicos não levam em conta somente seus interesses próprios, mas também o contexto institucional, em particular as regras jurídicas, morais e tradicionais (Raud-Mattedi, 2005b).

\section{PERCURSO METODOLÓGICO}

Este artigo tem como características metodológicas fundamentais o tipo de pesquisa descritivo-analítica, conforme Selltiz et al. (1975), por descrever o caso do mercado da tecelagem tradicional como construção social a partir de suas características específicas, imersas em relações socioeconômicas no município de Resende Costa (MG). Portanto, descreve e analisa esse mercado local, aqui entendido como delimitação espacial, geográfica e temporal. Esse tipo de pesquisa tem como objetivo primordial a descrição de características de determinada população ou fenômeno ou, então, o estabelecimento de relações entre variáveis. Uma de suas características mais significa- 
tivas está na utilização de técnicas padronizadas de dados, como o questionário e a observação sistemática (Gil, 2006).

Os dados primários da pesquisa são quantitativos e foram coletados a partir de um survey, que é, conforme Babbie (1999), instrumento adequado para a observação sistemática de possíveis regularidades sociais. Como a pesquisa se destinou somente à população relacionada com o mercado da tecelagem, conforme Costa Neto (1999), essa pode ser caracterizada como população-objeto da pesquisa. A amostragem dessa populaçãoobjeto foi não probabilística e intencional (Babbie, 1999; Costa Neto, 1999), por entrevistar indivíduos em domicílios e em estabelecimentos comercias relacionados diretamente com alguma atividade do processo produtivo ou comercial da tecelagem tradicional do município.

Para a coleta de dados, foram elaborados dois questionários estruturados: domiciliar e comercial. Com o objetivo de preservar a identificação dos entrevistados nos domicílios e dos estabelecimentos comerciais pesquisados, suas denominações foram substituídas por códigos. As famílias de origem tiveram a substituição do sobrenome da família por um código composto pelas letras FO (Família de Origem) e por um numeral. Os estabelecimentos de comercialização de insumos tiveram a substituição de sua denominação por um código composto pela letra F (Fornecedor). Os compradores da produção dos domicílios tiveram a substituição de sua denominação por um código composto pela letra $\mathrm{C}$ (Comprador). Além desses códigos de fornecedores (Fn) e de compradores ( $\mathrm{Cn}$ ), existe o código para um único indivíduo, ou organização, que fornece insumos e compra produtos e serviços dos domicílios. Esse código foi representado pela justaposição do seu código de fornecedor com o seu código de comprador, ou seja, FnCn.

Essas variáveis foram organizadas no software Microsoft Excel versão Office-2003 e posteriormente importadas para o software Ucinet 6.272 for Windows (Borgatti; Everett; Freeman, 2002). Esse último software possibilitou a representação gráfica e a análise sociométrica da densi- dade da rede e da centralidade dos atores. Conforme Scott (2000), a análise de redes sociais pode ser realizada a partir da representação gráfica dos vínculos e de medidas sociométricas. Essas medidas são apropriadas para as características da relação a ser abordada neste trabalho. Trata-se de uma relação de dois níveis, ou seja, o ator-família da produção domiciliar, que possui vínculos em momentos de fornecimento ou de venda, que podem ser - de acordo com Hanneman e Riddle (2005), Borgatti e Everett (1997) e Breiger (1974) - expressos por meio de uma matriz binária retangular de afiliação, denominada 2-mode. Isso nos permite analisar, em termos objetivos, a densidade da rede e as medidas dos atores na estrutura da rede.

A densidade da rede é uma proporção de vínculos em relação ao total de vínculos possíveis (Hanneman; Riddle, 2005). O conceito de centralidade é, conforme Freeman, Roeder e Mulholland (1980), Freeman (2002), Hanneman e Riddle (2005) e Nadel (2002), o mais expressivo indicador a ser extraído de uma rede, por mostrar posições desempenhadas pelo ator na estrutura social.É demonstrado pelos graus de centralidade, proximidade e intermediação, e seus valores variam de "0" a "1". O grau de centralidade ou degree representa as ligações diretas que são definidas pelo número de conexões de um nó (ator) com os demais nós (atores) da rede; quanto maior o grau, maior a centralidade do ator. O degree, ou centralidade, de um ponto é simplesmente uma contagem que representa a proporção de vínculos em relação ao total de vínculos possíveis do ator com outros atores. O grau de proximidade, ou closeness, de um ator representa quão perto o ator está de todos os outros atores da rede, incluindo os vínculos diretos e indiretos. Esse grau é definido a partir do somatório dos menores caminhos entre um nó (ator) e, no mínimo, mais dois nós (atores) da rede; quanto maior o grau, maior a proximidade do ator com os demais. Portanto, é a distância geodésica média entre um nó (ator) com relação aos demais, pela posição que ele ocupa na curva de menor comprimento, que une dois pontos adjacentes. O grau de intermediação, ou 
betweenness, de um ator representa o número de geodésicos usando o nó (ator) como passagem para outros nós (atores), ou seja, a intermediação significa a posição do ator no caminho mais curto entre pares de atores. Portanto, quanto maior o grau, maior a intermediação do ator com os demais pela posição que ele ocupa na curva de menor comprimento, que une dois pontos adjacentes (Freeman; Roeder e Mulholland, 1980; Freeman, 2002; Hanneman; Riddle, 2005; Nadel, 2002).

\section{PRODUÇÃO DOMICILIAR E ORGANIZAÇÃO COMERCIAL DA TECELAGEM TRADICIONAL}

O mercado da tecelagem tradicional de Resende Costa foi caracterizado por meio de dados que correspondem a uma amostra intencional de 664 domicílios e 69 estabelecimentos comerciais. Para essa amostra, foram visitados 2.655 domicílios no perímetro urbano da sede do município, ${ }^{2}$ dos quais 796 foram autodefinidos pelos entrevistados como um domicílio em que existia alguma atividade produtiva da tecelagem tradicional. Desses, 109 moradores não responderam ao questionário, e outros 23 questionários foram excluídos da amostra. Foram visitados 76 estabelecimentos comerciais formais de insumos e produtos da tecelagem do município, que tinham funcionamento diário para atendimento a consumidores, dos quais 69 proprietários responderam ao questionário.

\section{Produção domiciliar}

O domicílio produtor de peças é o mais frequente e representa $64,6 \%$ de todos os domicílios entrevistados. Existem também os domicílios que associam duas funções, como a de fornecedor de novelos de retalho e produtor de peças, representando 6\% das entrevistas. A maioria dos entrevistados (36,7\%) está no mercado de produção há

${ }^{2}$ A Prefeitura Municipal de Resende Costa, por meio do Setor de Cadastros, emitiu um relatório que contabilizou um total de 3.178 imóveis edificados na sede do município em julho de 2009 (Resende Costa, 2009). menos de cinco anos. Os dados indicam, por meio do aumento gradativo entre 5 e 20 anos, que o mercado da tecelagem tradicional expandiu suas atividades nos últimos 10 anos.

Para 26,8\% dos respondentes, o maior problema da tecelagem tradicional foi a falta de retalhos, seguidos por $20 \%$ que consideram a remuneração baixa. É interessante observar que a maioria dos problemas relacionados com a produção está associada à falta de insumos, de equipamentos e de trabalhadores, e que somente para $0,9 \%$ dos entrevistados o problema do domicílio produtor estava associado a questões de demanda, o que corrobora a indicação de que esse mercado vivenciou um momento de expansão.

Existiam 1.072 indivíduos trabalhando diretamente com a tecelagem tradicional na produção domiciliar. A maioria das unidades produtoras empregava, em suas atividades, no mínimo um trabalhador, o que representava $38,7 \%$ dos domicílios e, no máximo, 15 trabalhadores, que representavam 1,6\% dos domicílios. Os entrevistados, em 2009, afirmavam que, em 59,2\% dos domicílios, eles trabalhavam sozinhos, em $25,15 \%$ trabalhavam com alguém da família e as demais formas de associação para o trabalho foram relacionadas ao morador com sua família e trabalhadores de outros domicílios.

A ocupação da produção têxtil doméstica era representada, em sua maioria, pelo sexo feminino (73,8\%); entretanto, os homens $(26,2 \%)$ também têm espaço no mercado de produção da tecelagem tradicional municipal. A maioria dos trabalhadores - 54,7\% - possuía ensino fundamental incompleto, $16,8 \%$ ensino médio completo, $12,5 \%$ ensino fundamental completo e $12,0 \%$ ensino médio incompleto. Os trabalhadores são adultos em sua maior parte, já que $47,3 \%$ estavam na faixa entre 18 e 38 anos e 28,9\% entre 39 e 59 anos. Os idosos constituíram a terceira faixa mais expressiva, representando $10 \%$ dos trabalhadores. A faixa de renda mais frequente foi a de até meio Salário Mínimo (SM), que representava 53,8\% dos trabalhadores, seguida pela faixa de meio a 1,5 SM, que representava $32,7 \%$, e a de 1,5 a $3,5 \mathrm{SM}$, que 
correspondeu a 10\%. A remuneração é variável por produtividade dos trabalhadores e permitia uma jornada de trabalho flexível. A maior parte dos trabalhadores - 22,5\% - tinha uma jornada de oito horas, mas também havia 17,0\% que trabalhavam durante seis horas, $15,0 \%$, quatro horas, $13,6 \%$, cinco horas, $10,1 \%$, menos de três horas, 7,0\%, sete horas, 4,8\% dez horas, 2,6\% acima de onze horas, e 1,7\% nove horas. 5,7\% dos entrevistados não responderam. Os entrevistados responsáveis pelos domicílios produtores consideravam como a principal reclamação dos trabalhadores as dores (31,3\%), seguidas de baixa renda $(29,2 \%)$, insumos $(7,2 \%)$, doenças $(4,5 \%)$, entre outras queixas.

Os materiais de uso mais frequentes no processo produtivo da tecelagem são: retalho $(57,0 \%)$, linha e retalho (19,9\%), linha (16,5\%), retalho e fiado $(4,6 \%)$, retalho e outros materiais $(0,7 \%)$, lã $(0,4 \%)$ e algodão $(0,1 \%)$. Ocorreram erros de preenchimento no roteiro de entrevistas $(0,7 \%)$. A origem do fornecimento desses materiais foi respondida por 658 entrevistados, dos quais 41,6 \% compravam-nos nos estabelecimentos comerciais do município, enquanto 58,4\% não compram esses insumos e tinham acesso por meio do comprador de seus produtos. As 664 unidades de produção domiciliar, que consomem aproximadamente $20 \mathrm{t}$ de linha e $103 \mathrm{t}$ de retalho, transformaram-nos em vários produtos da tecelagem tradicional, com equipamentos específicos do processo produtivo. Os equipamentos mais frequentes nos domicílios eram tesouras e teares $69,4 \%$, tesouras $24,7 \%$ e teares $4,0 \%$, entre outros de menor incidência. Foi informada por 483 entrevistados a existência de 848 teares, com a incidência por domicílio de, no mínimo, 1 e no máximo 17 teares. Dos entrevistados, 610 relataram a existência de 1.396 tesouras, com a incidência por domicílio de, no mínimo, 1 e, no máximo, 15 tesouras. A propriedade dos teares informada pelos 483 entrevistados que responderam a essa questão foi de $80,8 \%$ dos moradores; $19,2 \%$ dos teares não eram de propriedade dos moradores. Os 102 entrevistados que responde- ram sobre os teares de terceiros informaram que $72,5 \%$ eram de propriedade do comprador da produção e que $27,5 \%$ eram de propriedade de familiares.

Para a maioria dos entrevistados, em 2009, o principal produto domiciliar era prestação de serviços, com 42,1\% dos domicílios especializados no serviço de tecer, $6,9 \%$ no serviço de picar retalho, 4,6\% no serviço de enrolar o novelo de retalho, 1,4\% no serviço de acabar as peças e 1,2\% no serviço de tecer, enrolar e picar retalho. Outros produtos domiciliares são representativos, pois, conforme os entrevistados, 28,9\% dos domicílios eram especializados na produção e venda de peças da tecelagem, 5,8\% na comercialização de novelos de retalho e 4,4\% na venda de retalho picado. Outros 3,6\% dos domicílios tinham especializações diversas, ${ }^{3}$ e 1,1\% dos entrevistados não responderam sobre esta questão. As peças mais produzidas eram tapetinho, tapete, jogo americano e guardanapos. A produção unitária mensal, em 2009, foi de 131.088 tapetinhos, que, comparada com a que foi registrada por Santos, Silva e Moretti (1998), que se referiu à produção de 1996, indicou que, nos últimos 12 anos, a produção dessa peça aumentou aproximadamente em 240, 0\%.

Os entrevistados foram questionados sobre a produção e o valor de venda das peças e serviços prestados, e 643 informaram tanto a produção como o valor recebido pelo serviço prestado ou peça vendida. A partir dessas informações, é possível estimar que esses 643 domicílios produtores tinham uma receita mensal de $\mathrm{R} \$ 393.686,64$, com um faturamento domiciliar mínimo de $\mathrm{R} \$ 6,90$ e máximo de R\$13.500,00, o que, para a economia municipal, representa um montante de recursos anuais de $\mathrm{R} \$ 4.724 .239,68$. A receita média anual por domicílio, a partir da estimativa apresentada, é de R \$7.347,18. O destino da venda da produção domiciliar foi informado por 532 entrevistados que comercializavam as peças e serviços para 158 compradores locais, os quais, como vimos, eram os responsáveis não só pela compra, mas pelo forne-

${ }^{3}$ Respostas com frequência igual ou menor que três. 
cimento de insumos e definição de rotinas impessoais, ou seja, comerciais, de remuneração e programação da produção domiciliar.

\section{Organização comercial}

A relação de contribuintes do cadastro econômico da Prefeitura Municipal de Resende Costa (2009) registrava 95 lojas de artigos de artesanato em julho de 2009; desses, 76 foram visitados e 69 proprietários ou funcionários foram entrevistados. A função dos 69 estabelecimentos comerciais que tiveram entrevistas realizadas não se restringia ao escoamento da produção. Para 69,6\% dos proprietários, sua função era produzir e comercializar as peças, para 15,9\% era comercializar as peças e para $11,6 \%$ era fornecer insumos, produzir e comercializar as peças, ou seja, um proprietário fornecia insumos e outro, insumos e comercializava peças. A maior parte dos estabelecimentos, ou seja, $43,5 \%$, estavam exercendo suas funções há menos de cinco anos, seguidos por $30,4 \%$ que exerciam entre 5 e 10 anos, $20,3 \%$ entre 10 e 20 anos e $2,9 \%$ que eram os pioneiros e exerciam suas funções há mais de 20 anos. Para 87,0\% dos entrevistados, os recursos financeiros auferidos em seu estabelecimento comercial eram sua principal fonte de renda, e $13 \%$ tinham seu estabelecimento comercial como fonte de renda secundária. Os principais problemas relatados pelos proprietários dos estabelecimentos comerciais foram o grande número de concorrentes na cidade -29,0\% , remuneração pequena $16,0 \%$, falta de trabalhadores $16,0 \%$ e falta de retalhos $11,6 \%$.

Nos estabelecimentos comerciais, foram encontrados 191 trabalhadores que eram, em sua maioria, da própria família do proprietário. As ocupações mais frequentes estavam relacionadas com a atividade principal do estabelecimento, que era a de realizar a comercialização e a organização burocrática da produção; portanto, 39,1\% eram vendedores e $37,6 \%$ os próprios proprietários. Das pessoas ocupadas nos estabelecimentos comerci- ais, 70,0\% eram do sexo feminino e 30,0\% do sexo masculino. A maioria - 57,0\% - tinha o ensino médio completo, $16,1 \%$ o ensino fundamental completo, 9,3\% o ensino fundamental incompleto, $8,8 \%$ a educação superior completa, $5,2 \%$ o ensino médio incompleto, $2,6 \%$ a educação superior incompleta e 1,0\% não responderam. Os indivíduos ocupados nos estabelecimentos comerciais estavam, em sua maioria - 70,5\% - na faixa de idade entre 18 e 38 anos, $24,9 \%$ entre 39 e 59 anos, $3,6 \%$ entre 15 a 17 anos e $1 \%$ com mais de 60 anos. A distribuição dos trabalhadores pelas faixas de renda foi de $43,5 \%$ na faixa de meio a 1 SM, 39,4\% na faixa de 1,5 a 3,5 SM, 6,7\% na faixa de 3,5 a 5 SM, 4,2\% na faixa de até meio SM, $2,6 \%$ na faixa acima de $5 \mathrm{SM}$, e 3,6\% não responderam. A jornada diária de trabalho dos ocupados nos estabelecimentos comerciais foi de oito horas para $63,2 \%$, quatro horas para $8,8 \%$, nove horas para $6,7 \%$, doze horas para $6,2 \%$, seis horas para $5,7 \%$, cinco horas para $4,7 \%$, sete horas para $2,1 \%$, dez horas para $2,1 \%$, e $0,5 \%$ não respondeu sobre a jornada de trabalho.

Para 39,1\% dos proprietários, a reclamação mais frequente dos seus fornecedores era referente aos insumos, e especificamente, em 55,6\% das reclamações, eles estavam se referindo à falta de insumos, $18,5 \%$ à baixa qualidade, $7,4 \%$ ao preço elevado e $18,5 \%$ associavam as três causas. Os 20,3\% de proprietários que reclamavam da remuneração se referiam à pequena remuneração, e 5,8\% reclamavam de dores no corpo.

As relações com trabalhadores não se restringiam somente aos que estavam formalmente vinculados aos estabelecimentos comerciais. Tal fato fica evidente com a informação, dada por 54 proprietários, de que eles possuíam 543 fornecedores, sendo que havia estabelecimentos com, no mínimo, um fornecedor e, no máximo, 65 fornecedores, com uma média de 10 fornecedores por estabelecimento comercial. Desses, 49 proprietários possuíam fornecedores locais que representavam $66,5 \%$ dos fornecedores, sendo que os estabelecimentos tinham, no mínimo, 1 fornecedor e, no máximo, 36 fornecedores, com uma média de 7,4 
fornecedores locais por estabelecimento. A existência de fornecedores do município e de outras localidades se devia ao fato de que os estabelecimentos comerciais da tecelagem tradicional possuíam, no total, 2.323 tipos de artigos em 53 estabelecimentos comerciais, sendo que a quantidade mínima de variedade de produtos por estabelecimento comercial era de dois tipos e, no máximo, 466. Do total de tipos de produtos existentes nos 53 estabelecimentos comerciais, $54,33 \%$ deles eram originários da produção domiciliar da tecelagem tradicional de Resende Costa (MG).

As entrevistas com 51 proprietários permitiram a realização de algumas estimativas a partir de dados sobre as principais peças comercializadas, suas quantidades, preços e origem do município fornecedor. $\mathrm{O}$ faturamento bruto mensal estimado dos 51 estabelecimentos comerciais foi de $\mathrm{R} \$ 605.440,50$, sendo o faturamento mínimo de $\mathrm{R} \$ 230,00$ e o máximo de $\mathrm{R} \$ 110.600,00$, com um faturamento médio de $\mathrm{R} \$ 11.871,38$. O mercado consumidor da tecelagem tradicional do município, nos últimos anos, passou por uma modificação no perfil do consumo. Essa mudança está no fato de que, atualmente, 20,2\% do destino da comercialização eram para turistas que frequentavam os estabelecimentos. Já no estudo de Santos, Silva e Moretti (1998), a comercialização se destinava somente a lojistas de outros municípios e estados.

As peças da tecelagem tradicional do município que compunham o portfólio de produtos dos estabelecimentos comerciais eram produzidas, conforme os proprietários, nos seguintes locais: 40,6\% nos domicílios dos fornecedores, $16,0 \%$ nos domicílios dos fornecedores e em galpão do proprietário do estabelecimento, 7,2\% no domicílio do proprietário do estabelecimento, $5,8 \%$ nos domicílios dos fornecedores e no do proprietário do estabelecimento, 2,9\% em galpão do proprietário do estabelecimento, 2,9\% no próprio estabelecimento comercial; $24,6 \%$ dos proprietários não responderam sobre o local de produção.
O galpão não era o único tipo de ativo fixo que os proprietários tinham investido nesse mercado, posto que, dos 69 proprietários entrevistados, 42 afirmaram possuir teares e, desses, 38 relataram que possuíam um total de 230 teares, tendo cada proprietário, no mínimo, um, e, no máximo, 23 teares, com uma média de 6 teares. Os proprietários dos estabelecimentos comerciais que afirmaram possuir teares (42 entrevistados) também informaram que 33,0\% desses equipamentos estavam nos domicílios dos fornecedores, $26,1 \%$ nos seus próprios domicílios, $19,5 \%$ nos domicílios dos fornecedores e em galpão de sua propriedade, $14,3 \%$ em galpão de sua propriedade e $7,1 \%$ nos domicílios dos fornecedores e no estabelecimento comercial.

\section{ESTRUTURA SOCIAL DO MERCADO DA TECELAGEM TRADICIONAL}

A estrutura social desse mercado foi compreendida a partir dos interesses econômicos de indivíduos imersos em relações de produção e comercialização da tecelagem tradicional, em que a instituição família pôde propiciar condições de coesão social, exercendo o papel de regulação do contrato e de garantia dos direitos individuais daqueles que estão envolvidos diretamente com o processo produtivo. Para compreender essa realidade social, teremos, como ponto de observação, a produção domiciliar, o elo do mercado local que mais preserva uma singularidade da tecelagem tradicional desse território, já que o elo comercial caminha em um processo de transformação de um atacadista e varejista de produtos da tecelagem tradicional do município para um atacadista e varejista de artigos artesanais e de produção manual.

Como o locus principal da análise social é a produção domiciliar, inicialmente se analisa a rede de fornecimento de insumos para os domicílios produtores, portanto, a representação gráfica e a sociométrica se referem aos 275 entrevistados, que informaram sobre seus 29 fornecedores. Os entrevistados foram agrupados conforme os so- 
Figura 1 - Rede família-fornecedor

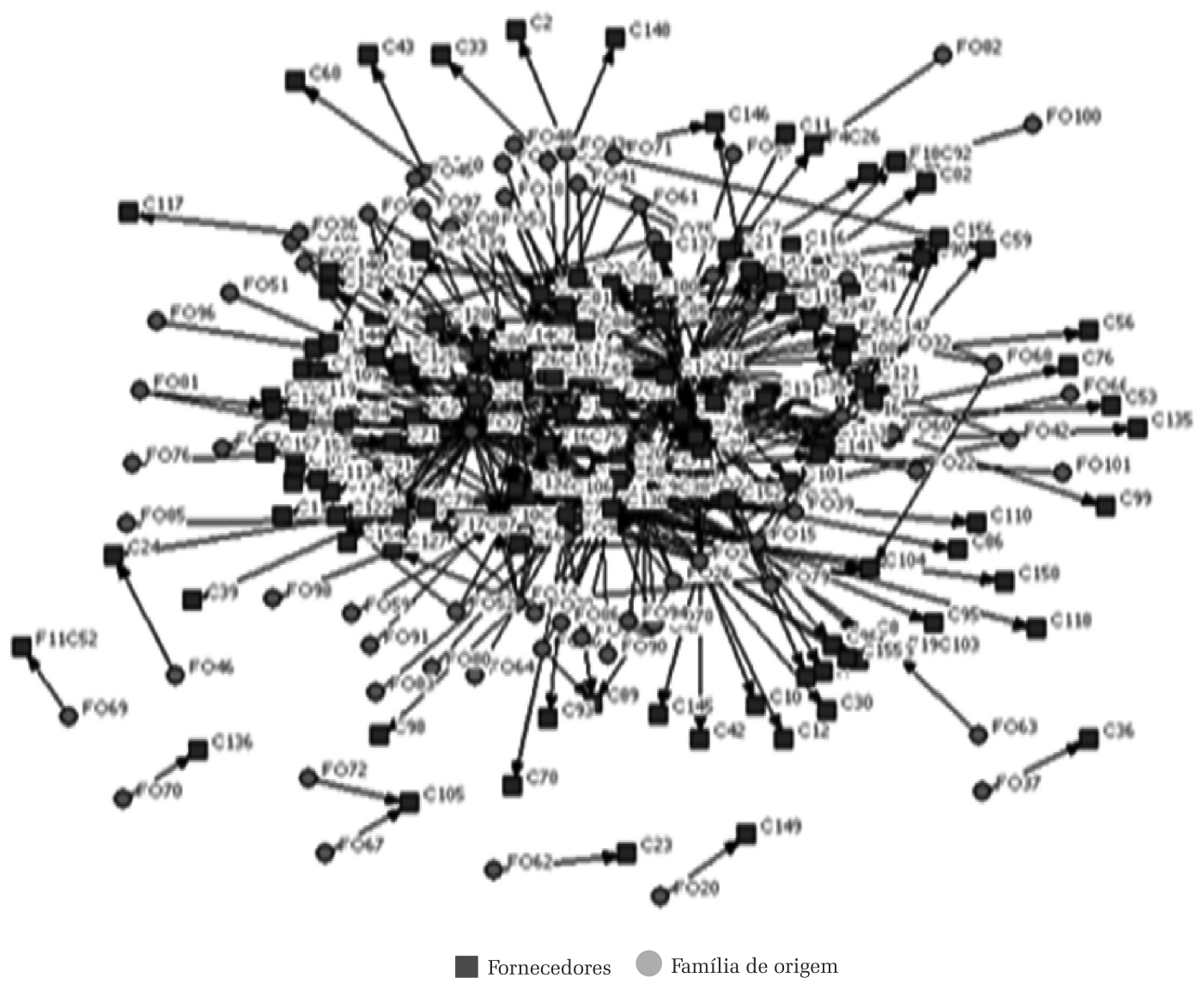

Fonte: Elaborado pelos autores.

brenomes de origem paterna, o que representou 57 famílias de origem, que informaram possuir 28 fornecedores. A rede de relacionamento da família de origem com os fornecedores de insumos está representada na Figura 1.

A rede família-fornecedor de insumo possuía, no máximo, 1.596 relações. Entretanto, a rede representada graficamente na Figura 1 tem densidade de 0,123, ou seja, representa 196 vínculos entre seus atores. A rede geral de famíliafornecedor indica que os atores-família FO12, FO7 e os atores-fornecedor F9C38, F7C31 e F10C46 têm os maiores graus de centralidade, respectivamente com graus $0,643,0,536,0,632$, 0,333 e 0,333 , indicando que eles são os atores mais centrais da rede. No que se refere ao grau de proximidade, os atores-família FO12, FO7 e os atores-fornecedor F9C38 e F7C31 são os mais próximos, respectivamente, com graus 0,903, 0,859,
0,750 e 0,610. A intermediação dessa rede tem como destaque os atores-família FO12, FO7 e os atoresfornecedor F9C38 e F10C46, respectivamente com os graus $0,179,0,117,0,364$ e 0,138 . De uma forma geral, os atores dos dois níveis - família e fornecedor - eram mais centrais e próximos do que intermediadores, como pode ser constatado pelo valor absoluto das medidas de centralidade, proximidade e intermediação.

A rede família-fornecedor tinha como ator principal o fornecedor F9C38. Essa característica expressa um possível reflexo estrutural da produção domiciliar de dependência dos elos produtivos dos fornecedores de insumos. Inclusive, é importante destacar que mais da metade dos entrevistados não adquirem insumos, que são fornecidos pelos compradores da produção domiciliar, os quais também são proprietários de aproximadamente 19\% dos teares existentes. A representa- 
Figura 2 - Rede geral família-comprador

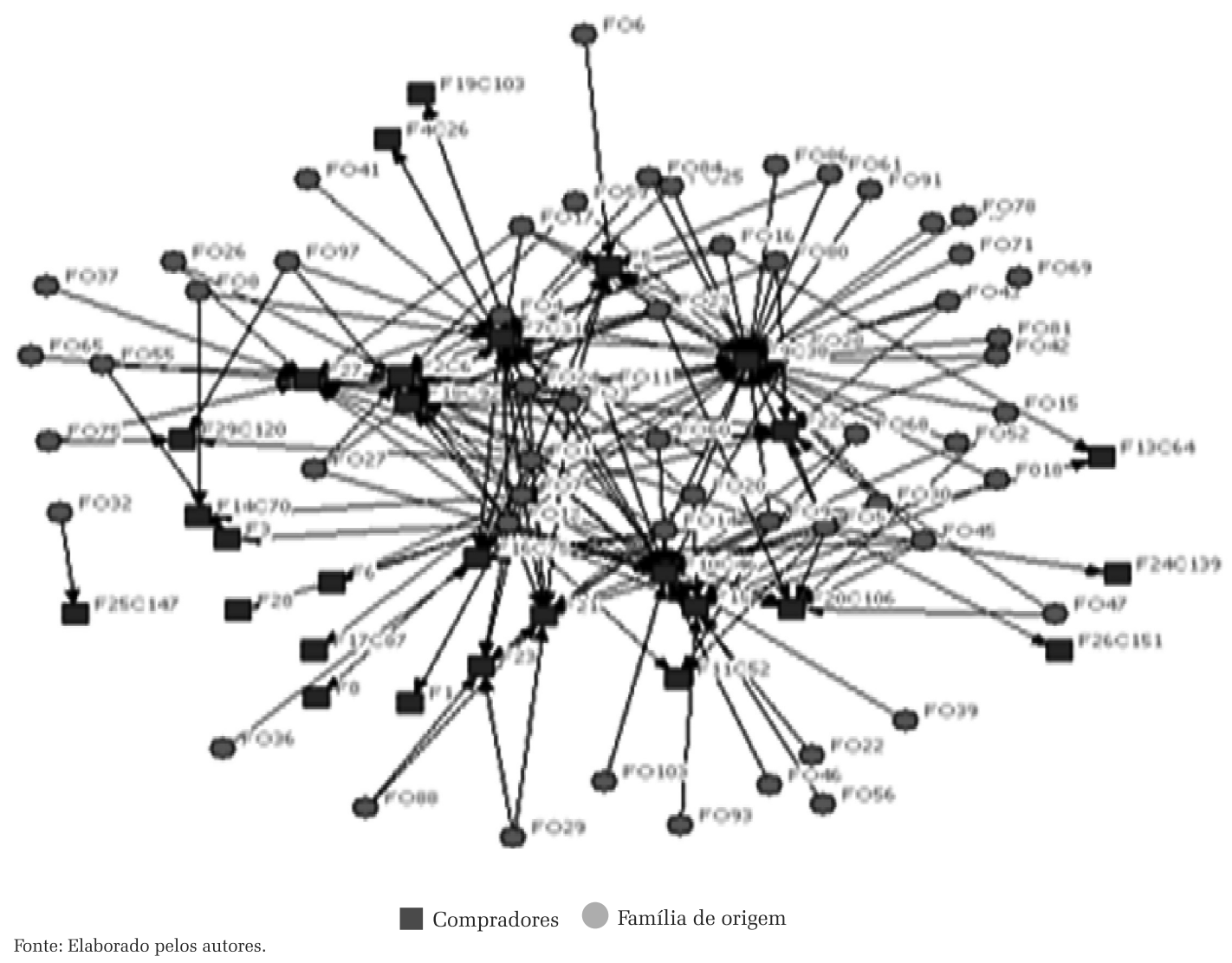

ção gráfica mostra, conforme Bourdieu (2005a), que o campo econômico do fornecimento era composto por uma rede de atores em dois níveis, que eram a família e o fornecedor, e os atores F9C38, FO12 e FO7 eram os mais bem posicionados. A troca mercantil existente na aquisição de insumos indica, de acordo com Granovetter (2002), que os indivíduos entrevistados estavam imersos em laços familiares que influenciavam sua racionalidade, principalmente por meio da posição de intermediação da família, o que encurta o caminho entre os atores da rede de fornecimento, os quais têm interesses econômicos mediados por relações familiares.

A rede de compradores da produção domiciliar das famílias era uma representação gráfica e sociométrica que se referia aos dados extraídos dos questionários sobre os 635 entrevistados que o fizeram sobre 88 famílias de origem e dos 532 entrevistados que responderam sobre os compradores da produção domiciliar. A rede geral de relaciona- mento família de origem e compradores está representada na Figura 2.

A rede família-comprador possuía, no máximo, 12.012 relações; entretanto, a rede representada graficamente na Figura 2 tem densidade de 0,036, ou seja, representa 434 vínculos entre seus atores. A rede geral família-comprador indica que os atores-família FO7, FO12 e os atores-compradores F9C38 e C130 têm os maiores graus de centralidade, respectivamente com 0,403, 0,377, 0,192 , e 0,179 , indicando que eles são os atores mais centrais da rede. No que se refere ao grau de proximidade, os atores-família FO7, FO12 e os atores-compradores C40, F2C6 e F9C38 são os mais próximos, respectivamente com os graus 0,644 , 0,629, 0,743, 0,743 e 0,734. A intermediação dessa rede tem como destaque os atores-família FO7 FO12 e os atores-compradores F9C38 e F2C6, respectivamente, com os graus 0,306, 0,275, 0,061 e 0,057. De uma forma geral, os atores dos dois níveis eram 
mais próximos doquecentrais eintermediadores, como pode ser constatado pelo valor absoluto das medidas de centralidade, proximidade e intermediação.

A rede família-comprador tinha como destaque os componentes principais, que eram os atores FO7 e FO12. Essa característica dessa rede expressava um possível reflexo estrutural de características do mercado da tecelagem tradicional de Resende Costa (MG). Conforme Silva (2010), 16,9\%, dos 664 entrevistados, definiram a tradição familiar como a principal motivação para ingressar no mercado, $61,9 \%$ foram socializados no trabalho com familiares. Portanto, os resultados das medidas dos atores na rede família-comprador, que identificam os atores do nível família de origem como os mais centrais e encurtam os caminhos da rede com sua intermediação, indicam a família como o laço de influência da ação econômica, mas também identificam os atores do nível comprador como os mais próximos de todos os atores, por propiciarem o escoamento da produção da maioria dos domicílios.

As redes família-fornecedor e família-comprador configuram o mercado do sistema produtivo da tecelagem tradicional de Resende Costa (MG), que consiste basicamente da emergência de relações sociais entre indivíduos (Swedberg, 1994), em um aglomerado de empreendimentos domiciliares produtivos e comerciais estruturados socialmente. Portanto, fica evidente, conforme Granovetter (1994), a existência de grupos econômicos em que existe a ocorrência da solidariedade e de uma estrutura social. Tal solidariedade, nesse mercado produtivo, ocorre entre indivíduos com interesses econômicos imersos em laços ou vínculos sociais, o que facilita a circulação de informações e assegura confiança ao limitar os comportamentos oportunistas (Granovetter, 2002) de indivíduos em relações econômicas informais. Portanto, o sistema produtivo da tecelagem tradicional de Resende Costa (MG) confirma, conforme Granovetter (1973) e Polanyi (2000), a perspectiva de que a ação econômica é socialmente situada, sendo o sistema econômico uma mera função da organização social. Fica evidente, por- tanto, conforme Swedberg e Granovetter (1992), que essa rede é um conjunto regular de contratos sociais, ou seja, de conexões sociais similares entre indivíduos e grupos familiares.

\section{CONSIDERAÇÕES FINAIS}

O que se observou, nas relações de trabalho e produtivas do mercado analisado, é que existe uma conciliação, mesmo que assimétrica, do interesse individual do homo economicus e da população local. Os comerciantes buscaram maximizar seus lucros a partir de uma base comum de conhecimento tradicional, o que viabilizou a remuneração da força de trabalho local detentora desse saber e que está imersa em relações entre famílias e comerciantes. Tanto os produtores domiciliares da tecelagem tradicional quanto os proprietários dos estabelecimentos comerciais foram afetados em suas ações e atitudes por relações sociais, como na socialização do trabalho e da confiança no relacionamento de troca nos momentos de satisfação das necessidades de fornecimento ou de venda da produção domiciliar. Entretanto, a estrutura social desse mercado em redes família-fornecedor e família-comprador indicam que as famílias FO7 e FO12 são mais poderosas por intermediarem as relações da rede em que a produção domiciliar é comercializada, e o fornecedor F9C38 é o ator mais poderoso da rede de fornecimento de insumos para produção domiciliar.

A organização social desse mercado era caracterizada por uma produção domiciliar dispersa e uma organização burocrática central que controlava os serviços produtivos a partir do fornecimento de insumos, conforme a análise de redes indica. Entretanto, a construção social desse mercado demandou laços e, consequentemente, confiança entre os elos da cadeia de produção da tecelagem tradicional local e, também, internamente, nos elos entre os indivíduos que a compõem e que foram coordenados pelos fornecedores de insumos e compradores da produção domiciliar. A localização dos 
elos do mercado da tecelagem tradicional analisada configura a materialização da articulação entre o capital social das famílias, que garante um ambiente de ordenamento social, mesmo diante de conflitos decorrentes da escassez de insumos, que são centralizados pela atuação de atores que concentram seu fornecimento.

As redes representadas graficamente mostram, portanto, a estrutura social do mercado da tecelagem tradicional, especificamente a partir de relações de troca mercantil nos momentos de compra de insumos e venda da produção domiciliar. Essa estrutura, entretanto, não é a única, conforme Smelser e Swedberg (1994), já que o foco de análise da rede, nesses processos econômicos, permite afirmar que as redes de famílias mais frequentes eram mais densas e aproximavam mais as conexões e interações entre a economia e a sociedade. A posição dos atores de origem, principalmente FO7 e FO12, em especial na posição de intermediação, mostra que eles encurtavam os caminhos entre todos os outros atores no momento da venda da produção domiciliar e indica que, conforme Granovetter (1973), as ações nesse mercado estavam inseridas em estruturas familiares de relações e intercâmbios socioeconômicos, garantindo o abastecimento de determinados compradores.

As redes de família-fornecedor e família-
Granovetter (2002), em laços fortes, mas que também foram organizados burocraticamente pelos estabelecimentos comerciais, o que propiciou o estabelecimento e a estruturação de um mercado de tecelagem tradicional.

A organização social desse mercado era caracterizada por produção domiciliar dispersa e organização burocrática central que controla os serviços produtivos. Entretanto, a construção social desse mercado demandou laços e, consequentemente, confiança entre os elos da cadeia de produção da tecelagem tradicional local. Demandou também, internamente, os elos entre os indivíduos que a compõem e que foram coordenados pelos fornecedores de insumos e compradores da produção domiciliar. A localização dos elos do mercado da tecelagem tradicional analisada configura a materialização e legitimação de uma identidade regional que ocorre com a articulação entre o capital social das famílias e os interesses individuais de garantir a sobrevivência com a geração de renda por meio da economia informal.

Recebido para publicação em 20 de dezembro de 2011 Aceito em 27 de abril de 2012

\section{REFERÊNCIAS}

ABRAMOVAY, R. Anticapitalismo e inserção social dos mercados. Tempo Soc., São Paulo, v. 21, n. 1, p. 65-87, jun., 2009. Disponível em: http://www.fflch.usp.br/sociologia/temposocial/pdf/vol21n1/v21n1a04.pdf. Acesso em: 9 dez. 2012.

BABBIE, Earl. Métodos de pesquisas de survey. Belo Horizonte: Ed. UFMG, 1999.

BORGATTI, Ptephen S.; EVERETT, Martin G. Network analysis of 2-mode data. Social Networks, Pittsburgh, v. 19 n. 3, p. 243-269, ago., 1997.

BORGATTI, Ptephen S.; EVERETT, Martin G.; FREEMAN, Linton C. UCINET 6 for Windows - software for social network analysis. Harvard: Harvard Analytic Technologies, 2002.

BOURDIEU, Pierre. O campo econômico. Política \& Sociedade, Florianópolis, v.1, n.6, p.15-57, abr., 2005a. Disponível em: http://naui.ufsc.br/files/2010/09/Bordieu Ocampo-econ\%C3\%B4mico.pdf. Acesso em: 9 dez. $20 \overline{1} 2$.

The social structures of the economy. Cambridge: Polity Press, 2005b.

BREIGER, Ronald L. The duality of persons and groups. Social Forces, New York, v. 53, n. 2, p. 181-190, dez., 1974

COLEMAN, James S. Foundations of social theory. Cambridge: Havard University Press, 1990. 
COSTA NETO, Pedro L. O. Estatística. 17. reimp. São Paulo: Edgard Blücher, 1999.

ELSTER, Jon. Peças e engrenagens das ciências sociais. Rio de Janeiro: Relume-Dumará, 1994.

FREEMAN, Linton. C. Centrality in social networks: conceptual clarification. In: SCOTT, John (Ed.). Social network: critical concepts in sociology. London: Routledge, 2002. p. 238-263. v. 1.

FREEMAN, Linton C.; ROEDER, Douglas; MULHOLLAND Robert R. Centrality in social networks: II. Experimental results. Social Networks, Pittsburgh, v. 2, n. 2, p. 119-141, 1980. Disponível em: http://moreno.ss.uci.edu/29.pdf. Acesso em: 9 dez. 2012.

GIL, Antonio C. Como elaborar projetos de pesquisa. São Paulo: Atlas, 2006.

GRANOVETTER, Mark, Economic action and social structure: the problem of embeddedness. In: BIGGART, Nicole (Eds.). Readings in economic sociology. Malden: Wiley-Blackwell, 2002. p. 154-167.

Business groups. In: SMELSER, Neil; SWEDBERG, Richard (Ed.). The handbook of economic sociology. Princeton: Princeton University Press, 1994. p. 453-475

The sociological and economic approches to labor market analysis: a social structural view. In GRANOVETTER, Mark; SWEDBERG, Richard (Ed.). The sociology of economic life. Boulder: Westview Press, 1992. p. 233-264.

The strength of weak ties. American Journal of Sociology, v. 78, n. 6, p. 1360-1380, maio, 1973. Disponível em: http://sociology.stanford.edu/people/ mgranovetter/documents/granstrengthweakties.pdf. Acesso em: 9 dez. 2012.

HANNEMAN, Robert A.; RIDDLE, Mark. Introduction to social network methods. Riverside: University of Califórnia, 2005. Disponível em: http://www.faculty.ucr.edu/ hanneman/nettext/. Acesso em: 9 dez. 2012.

MACEDO, Concessa V. A indústria têxtil, suas trabalhadoras e os censos da população de Minas Gerais do século XIX: uma reavaliação. Varia Historia, Belo Horizonte, v. 22, n. 35, p. 207-232, jan./ jun., 2006.

NADEL, S. F. Degrees of abstration. In: SCOTT, John (Ed.). Social network: critical concepts in sociology. London: Routledge, 2002. p. 53-59. v. 1.

SCOTT, John (Ed.). Social network: critical concepts in sociology. London: Routledge, 2002.

NOBRE, R. F. Perspectivas da razão: Nietzsche, Weber e o conhecimento. Belo Horizonte: Argumentum, 2004.

POLANYI, Karl. A grande transformação: as origens de nossa época. 8. ed. Rio de Janeiro: Campus, 2000.

RAUD-MATTEDI, Cécile. Bourdieu e a nova sociologia econômica. Tempo Soc., São Paulo, v. 19, n. 2, p. 203-232, nov., 2007. Disponível em: http://www.scielo.br/pdf/ts/ v19n2/a08v19n2.pdf. Acesso em: 9 dez. 2012.

Análise crítica da sociologia econômica de Mark Granovetter: os limites de uma leitura do mercado em termos de redes e imbricação. Política \& Sociedade, Florianópolis, n. 6, p. 59-82, abr., 2005a. Disponível em: http://www.periodicos.ufsc.br/index.php/politica/article/ view/1931/1698. Acesso em: 9 dez. 2012.

A construção social do mercado em Durkheim e Weber: análise do papel das instituições na sociologia econômica clássica. Rev. bras. Ci. Soc., São Paulo, v. 20, n. 57, p.127-208, fev., 2005b. Disponível em: http:// www.scielo.br/pdf/rbcsoc/v20n57/a08v2057.pdf. Acesso em: 9 dez. 2012.
RESENDE, A. P. M. Entre fios e panos: mulheres nas Minas Gerais. 2001. 72 f. Monografia (Especialização em História de Minas do Século XIX) - Departamento de Ciências Sociais, Fundação de Ensino Superior de São João Del-Rei, São João Del Rei, 2001.

RESENDE COSTA (MG). Relatório de Imóveis por Bairros - edificados. Resende Costa: Setor de Arrecadação, 2009. $84 \mathrm{p}$.

SANTOS, Micenio C.; SILVA, G. M.; MORETTI, A. R. Artesanato: contando teares. São João Del Rei: Funrei. 1998.

SCOTT, John. Social network analysis. 2. ed. London: Sage, 2000

SELLTIZ, Claire et al. Métodos de pesquisa nas relações sociais. São Paulo: EPU, 1975.

SILVA, Gustavo M. Mercados como construções sociais: divisão do trabalho, organizacão e estrutura social de um mercado em um território municipal. 2010. 358 f. Tese (Doutorado em Sociologia) - Faculdade de Filosofia e Ciências Humanas, Universidade Federal de Minas Gerais, Belo Horizonte. Disponível em: http://www.bibliotecadigital.ufmg.br/ dspace/handle/1843/VCSA-874GMS. Acesso em : 9 dez. 2012

SMELSER, Niel; SWEDBERG, Richard. The sociological perspective on the economy. In: (Ed.). The handbook of economic sociology. Princeton: Princeton University Press. 1994. p. 3-26.

STEINER, Philippe. A sociologia econômica. São Paulo: Atlas, 2006

SWEDBERG, Richard. A sociologia econômica do capitalismo: uma introdução e agenda de pesquisa. In: MARTES, Ana C. B. (Org.). Redes e sociologia econômica. São Carlos: EdUFSCAR, 2009. p. 161-197.

Markets as social structures. In: SMELSER, Niel SWEDBERG, Richard (Ed.). The handbook of economic sociology. Princeton: Princeton University Press:1994. p. 255-282

Sociologia econômica: hoje e amanhã. Tempo Soc., São Paulo, v. 16 n. 2 p. 7-34, nov. 2004. Disponível em: http://www.scielo.br/pdf/ts/v16n2/v16n2a01.pdf. Acesso em: 9 dez. 2012.

GRANOVETTER, Mark. Introduction. In (Eds.). The sociology of economic life. Boulder: Westview Press, 1992. p. 1-26. 


\section{TRADITIONAL SYSTEMS OF PRODUCTION AND IMMERSION OF ECONOMIC INTERESTS IN SOCIAL RELATIONSHIPS}

\author{
Gustavo Melo Silva \\ Jorge Alexandre Barbosa Neves
}

The municipality of Resende Costa (MG) has had a tradition of domestic textile production since the $18^{\text {th }}$ century. However, since the end of the $20^{\text {th }}$ century it has been a market of traditional weaving. This article analyzes the social construction of this municipal market based on records from the $18^{\text {th }}$ and $19^{\text {th }}$ centuries, research from late $20^{\text {th }}$ century and also preliminary data gathered in 2009 from 664 domestic producers and 69 businesses. This market was made up of uneven production in the homes, the division of labor, and the commercial bureaucratic organization which controls their production services to meet consumer demands and solidarity among individuals with economic interests immersed in family relationships, which make up the density and moral discipline of this municipal market of traditional weaving.

KeY woRDs: traditional production system, economic sociology, socioeconomic structure.

\section{SYSTÈMES DE PRODUCTION TRADITIONNELS ET IMMERSION D'INTÉRÊTS ECONOMIQUES DANS LES RELATIONS SOCIALES}

\author{
Gustavo Melo Silva \\ Jorge Alexandre Barbosa Neves
}

La production familiale textile est une tradition de la commune de Resende Costa (Etat de Minas Gerais) depuis le XVIIIe siècle. Cependant ce qu'on peut voir à partir de la fin du XXe siècle, c'est un marché de tissage traditionnel. Cet article présente l'analyse la construction sociale de ce marché municipal en se basant sur des données historiques des XVIIIe et XIXe siècles, des recherches faites à la fin du XXe siècle et des données primaires recueillies en 2009 auprès de 664 familles de producteurs et 69 magasins. La construction de ce marché s'est faite grâce à la production dispersée des familles, la division du travail et l'organisation bureaucratique commerciale qui contrôle ses services productifs afin de répondre aux exigences de consommation et de solidarité entre individus dont les intérêts économiques sont incrustés dans les relations familiales. Et ce sont justement ces familles qui constituent la densité et la discipline morale du marché municipal du tissage traditionnel.

Mots-CLÉs: système productif traditionnel, sociologie économique, structure socioéconomique.

Gustavo Melo Silva - Doutor em Sociologia. Professor do Departamento de Ciências Administrativas e Contábeis da Universidade Federal de São João del-Rei (UFSJ). Publicações recentes: BRASIL, F. P.D.; SILVA, G.M.; CARNEIRO, R.; ALMEIDA M. E. Gestão democrática das cidades e instituições participativas: tendências no contexto brasileiro recente. Economia global e gestão. v. 17, p. 117-134, 2012; SILVA, G. M.; NEVES, J. A. B. Estruturação organizacional e realidade socioeconômica: o caso da indústria criativa minero artesanal em três municípios de Minas Gerais. Organizações Rurais e Agroindustriais (UFLA), v. 13, p. 53-62, 2011.

Jorge Alexandre Barbosa Neves - Doutor em Sociologia. Realizou pós-doutoramento no Instituto de Pesquisas Sociais (INPSO), da Fundação Joaquim Nabuco (FUNDAJ), em Recife-PE. Professor Associado da Universidade Federal de Minas Gerais, onde ocupa o cargo de Diretor da Faculdade de Filosofia e Ciências Humanas. É um dos Editores da Population Review, desde julho de 2009. Publicações recentes: FERNANDES, Daniele Cireno; NEVES, Jorge Alexandre. Urban bias in development and educational attainment in Brazil. The Journal of Developing Areas (Online), v. 43, p. 271-288, 2010; HELAL, Diogo Henriques; NEVES, Jorge Alexandre. Burocracia e inserção social: uma proposta para entender a gestão das organizações públicas no Brasil. Sociologias (UFRGS. Impresso), v. 12, p. 312-340, 2010; NEVES, Jorge Alexandre; FERNANDES, Daniele Cireno; HELAL, Diogo H. Region, industry, and intergenerational status transmission in urban Brazil. Population Review, v. 46, p. 12, 2007. 